\title{
Commentary \\ Akt2: a role in breast cancer metastasis
}

\author{
Noan-Minh Chau and Margaret Ashcroft
}

\author{
Cancer Research UK Centre for Cancer Therapeutics, Institute of Cancer Research, Sutton, Surrey, UK \\ Corresponding author: Margaret Ashcroft (e-mail: margaret.ashcroft@icr.ac.uk) \\ Published: 4 November 2003 \\ Breast Cancer Res 2004, 6:55-57 (DOI 10.1186/bcr739) \\ (C) 2004 BioMed Central Ltd (Print ISSN 1465-5411; Online ISSN 1465-542X)
}

\begin{abstract}
Metastasis in breast cancer significantly increases morbidity and mortality. The 5-year survival rate reduces from $90 \%$ for localised disease to about $20 \%$ once metastasis has taken place. The phosphoinositide 3-kinase/Akt signalling pathway has an important role in cell motility, invasion and metastasis. However, the precise contribution of the Akt kinase family members, Akt1, Akt2 and Akt3, in mediating these processes is unclear. The possibility that they have distinct functions in tumour progression is particularly interesting.
\end{abstract}

Keywords: Akt2, invasion, metastasis, phosphoinositide 3-kinase, PTEN

\section{Introduction}

A recent study by Arboleda and colleagues has addressed the role of Akt2 in metastasis with the use of human breast and ovarian cancer cell lines [1]. This study revealed that Akt2 was sufficient to mediate phosphoinositide 3-kinase (PI3-K)-dependent effects on the metastatic process in these cells. Akt2, also known as PKB $\beta$, is one of three isoforms of Akt [2]. It is a serine/threonine protein kinase and a downstream target of PI3-K. The mechanism of action is the same for all Akt isoforms: activation is initiated by growth factors binding to their transmembrane receptors, which in turn activate PI3-K either directly or indirectly (via Ras). $\mathrm{PI} 3-\mathrm{K}$ then catalyses the conversion of phosphatidylinositol4,5-bisphosphate to phosphatidylinositol-3,4,5-trisphosphate, a second messenger that is essential for the recruitment of Akt to the plasma membrane. Once anchored, Akt can be phosphorylated and activated by phosphatidylinositol-3,4,5-trisphosphate-dependent kinase (PDK1). Activated Akt promotes the transcription of a range of genes, in particular those involved in cellular transformation and proliferation $[3,4]$. The PI3-K/Akt signalling pathway contributes to many types of human malignancies [5-7].

During the last few years, specific signalling roles for individual Akt isoforms have begun to emerge [5,8-10]. Although much attention has focused on understanding the role of Akt1 in cell survival and proliferation, the study by Arboleda and colleagues [1] has highlighted the importance of Akt2 in metastasis in breast and ovarian cancer cells. This work reinforces the idea that members of the Akt family have distinct functional roles in tumour progression.

\section{Akt2 and the metastatic process}

The tumorigenicity of Akt2 is evident. Activation of Akt2 has been shown in ovarian [10] and breast [8] cancers. Work performed in NIH ЗТ3 fibroblast cells, in which Akt2 was exogenously expressed, showed malignant transformation [11], and PANC1 pancreatic cancer cells expressing antisense Akt2 RNA could suppress invasion and tumour formation in nude mice [12]. However, the effect of Akt2 in vivo has not previously been investigated. Arboleda and colleagues approached this by generating stable breast and ovarian cancer cell lines expressing the full-length Akt2 cDNA. They noted that the Akt2-overexpressing cells were able to migrate readily through matrigel and could survive longer than the parental control cell line under nutrient-poor conditions. Morphological changes, such as lamellipodium formation and membrane ruffling, which are features of migrating cells [13], were also observed. Because part of the metastatic process involves the migration of detached cancer cells from the primary site, perhaps it was these observations that 
prompted the investigators to explore the role of Akt2 in metastasis.

\section{Akt2 effects in vitro}

In vitro work performed by Arboleda and colleagues on cell adhesion and invasion employed standard assays [1]. The main finding was that the Akt2 transfectants resulted in increased attachment and invasion through collagen IV. These properties were associated with an increased expression of $\beta_{1}$-integrins, which are cell surface receptors for extracellular matrix and basement membrane components such as collagen IV and laminin [14]. Neutralising antibodies against $\beta_{1}$-integrin were able to reduce invasion significantly. These experiments were performed in one clonal cell line, Akt2-overexpressing MDA-MB-435 breast cancer cells. It would have been interesting to determine whether other cancer cell types that have high levels of endogenous Akt2, for example OVCAR3 cells, gave similar results. Similarly, it would have been interesting to assess the possibility that other Akt isoforms also contributed to the elevated $\beta_{1}$-integrin levels. Nevertheless, the specific importance of Akt2 in mediating the metastatic process in breast cancer cells in vitro was confirmed by showing that cells transfected with Akt1 and Akt3 had only minor effects in invasion assays [1].

The caveat in these confirmation studies was that Arboleda and colleagues used MDA-MB-435 HER-2 cells. The observations made might therefore not have reflected the invasive potential solely attributable to Akt2. This is because overexpression of human epidermal growth factors receptor-2 (HER-2)/neu has been shown to correlate with elevated expression of Akt2 and increased Akt kinase activity [15]. It is therefore possible that the effects of exogenous Akt2 expression on invasion of these cells were enhanced by the contribution of HER-2/neu or that HER-2/neu overexpression contributed to the activation of the other Akt isoforms that led to the increased invasion by Akt2 overexpression [1]. Extending these experiments to include a number of cellular backgrounds would ensure that the observations made were not cell-type specific.

\section{Akt2 effects in vivo}

A demonstration of increased adhesion and invasion does not necessarily translate to an ability for cells to metastasise, because these are only two steps in a complex process in which many genes are involved. The contribution of a particular molecule to metastasis can only be convincingly proven by performing studies in vivo. Arboleda and colleagues showed that Akt2-overexpressing breast cancer cells resulted in the successful formation of metastases when injected into nude mice, suggesting that Akt2 is likely to mediate the regulation of a large number of metastatic genes. The Akt2 transfectants developed multiple macroscopic and microscopic these retained Akt2 expression, as confirmed by immunohistochemistry. The parental cells, in contrast, generated one or two localised but larger tumour masses [1]. The difference in size was correlated with an increased expression of $\beta_{1}$-integrin in the Akt2 transfectants. It has already been shown that $\beta_{1}$-integrins can mediate cell migration by interacting with the extracellular matrix components and reducing cell-cell interaction [16]. It therefore follows that the increased expression of $\beta_{1}$-integrin could contribute to the more widespread metastases and smaller tumours observed in the Akt2 transfectants.

The role of Akt2 in vivo was confirmed by using a kinasedead (inactive) Akt2 mutant (K181M-Akt2), which significantly reduced not only metastases but also tumour growth [1]. This study was performed in xenografts derived from SKOV3(K181M)Akt2 cells (an ovarian cancer cell line overexpressing kinase-dead Akt2) [1]. Unfortunately, Arboleda and colleagues did not take the opportunity to compare the effects of this mutant in vivo in Akt1-transfected or Akt3transfected cells. The sequences surrounding the regulatory phosphorylation sites within the kinase domain of Akt2 are highly conserved between all Akt isoforms [17], and it is possible that the K181M-Akt2 dominant-negative could affect other Akt isoforms. Details of the specificity of the $\mathrm{K} 181 \mathrm{M}$-Akt2 construct and the Akt isoform expression pattern in the SKOV3(K181M)Akt2 cells would therefore have enabled Arboleda and colleagues to make more definitive conclusions about the role of Akt2. In addition, insight could potentially have been gained into which isoform, if any, commands the principal role in metastasis by using short interfering RNA (siRNA) technology.

One would speculate from the published data that both Akt1 and Akt3 have a role in the metastatic process, because Akt1 is highly oncogenic [18] and has been shown to increase migration and invasion of HT1080 human fibrosarcoma cells [19] as well as mouse mammary epithelial cells [20], and Akt3 expression has been observed in aggressive tumours [9], implying a high probability of transformation to a metastatic phenotype. In support of this, Arboleda and colleagues also observed that both Akt1 and Akt3 had better invasive ability than the parental cells, although to a smaller extent than Akt2 [1].

\section{Akt2 mediates PI3-K-dependent effects}

Several notable points about Akt2 and invasion in breast cancer are highlighted in this study. First, Akt2 needs to be activated for metastasis to develop. MDA-MB-435 cells expressing a kinase-dead Akt2 mutant had diminished invasion potential and were unable to form tumours or metastases in vivo. The importance of Akt activation in the metastatic process was previously shown in ovarian [10] and pancreatic [21] cancer cells. Second, Akt2 cooperates with other oncogenic signals to mediate metastatic processes. Overexpression of Akt2 in normal cells pro- 
duced no effects [1]. Indeed, Akt2 was not detected in normal tissue or benign tumour samples [22], whereas high levels were observed in stage III and IV ovarian cancers [10]. Third, PI3-K and other components of the PI3-K/Akt pathway can mediate cell invasion. This was demonstrated by the observation that overexpression of $p 110 \alpha$ (one of the catalytic subunits of PI3-K) or PDK1 could induce cell invasion analogous to that observed for Akt2 overexpression, and expression of phosphatase and tensin homologue deleted on chromosome ten (PTEN, a tumour suppressor protein that dephosphorylates $\mathrm{PI} 3-\mathrm{K}$ ) had the opposite effect on cell invasion [1]. Furthermore, wortmannin and LY294002, which are both inhibitors of PI3-K, blocked cell attachment and invasion in Akt2-overexpressing cells.

Of particular interest is a recent study using Akt1, Akt2 and p110 $\beta$ (one of the PI3-K catalytic subunits) siRNAs in HeLa cells to determine their relative effects on cell growth [23]. Although $\mathrm{p} 110 \beta$ siRNA and inhibitors of PI3-K completely inhibited cell growth of HeLa cells on matrigel, neither Akt1 nor Akt2 siRNA had any significant effect. It is therefore possible that not only are there distinct and overlapping roles for members of the Akt family in tumour progression, but these functions might also be cell-type specific.

\section{Conclusions}

The link between Akt2 and breast cancer has been elucidated in several studies [15,22], but the effect of Akt2 on tumour metastasis and growth in vivo has not been demonstrated until recently [1]. In an interesting study, Arboleda and colleagues have established a role for Akt2 in metastasis of breast cancer cells and have clearly shown the importance of the Akt pathway in the metastatic process, both in vitro and in vivo. Knowledge of the molecular basis for this now remains to be sought.

\section{Competing interests}

None declared.

\section{Acknowledgements}

We thank Professor Paul Workman for critical review of the manuscript.

\section{References}

1. Arboleda MJ, Lyons JF, Kabbinavar FF, Bray MR, Snow BE, Ayala R, Danino M, Karlan BY, Slamon DJ: Overexpression of AKT2/protein kinase B beta leads to up-regulation of $\beta_{1}$ integrins, increased invasion, and metastasis of human breast and ovarian cancer cells. Cancer Res 2003, 63:196-206.

2. Cheng JQ, Godwin AK, Bellacosa A, Taguchi T, Franke TF, Hamilton TC, Tsichlis PN, Testa JR: AKT2, a putative oncogene encoding a member of a subfamily of protein-serine/threonine kinases, is amplified in human ovarian carcinomas. Proc Natl Acad Sci USA 1992, 89:9267-9271.

3. Franke TF, Yang SI, Chan TO, Datta K, Kazlauskas A, Morrison DK, Kaplan DR, Tsichlis PN: The protein kinase encoded by the Akt proto-oncogene is a target of the PDGF-activated phosphatidylinositol 3-kinase. Cell 1995, 81:727-736

4. Scheid MP, Woodgett JR: Unravelling the activation mechanisms of protein kinase B/Akt. FEBS Lett 2003, 546:108-112.

5. Nicholson KM, Anderson NG: The protein kinase B/Akt signalling pathway in human malignancy. Cell Signal 2002, 14: 381-395.
6. Vivanco I, Sawyers CL: The phosphatidylinositol 3-kinase-Akt pathway in human cancer. Nat Rev Cancer 2002, 2:489-501.

7. Testa JR, Bellacosa A: Akt plays a central role in tumorigenesis. Proc Natl Acad Sci USA 2001, 98:10983-10985.

8. Sun M, Paciga JE, Feldman RI, Yuan Z, Coppola D, Lu YY, Shelley SA, Nicosia SV, Cheng JQ: Phosphatidylinositol-3-OH Kinase (PI3-K)/AKT2, activated in breast cancer, regulates and is induced by estrogen receptor $\alpha(E R \alpha)$ via interaction between $\mathrm{ER} \alpha$ and PI3-K. Cancer Res 2001, 61:5985-5991.

9. Nakatani K, Thompson DA, Barthel A, Sakaue H, Liu W, Weigel RJ, Roth RA: Up-regulation of Akt3 in estrogen receptor-deficient breast cancers and androgen-independent prostate cancer lines. J Biol Chem 1999, 274:21528-21532.

10. Yuan ZQ, Sun M, Feldman RI, Wang G, Ma X, Jiang C, Coppola D, Nicosia SV, Cheng JQ: Frequent activation of AKT2 and induction of apoptosis by inhibition of phosphoinositide-3-OH kinase/Akt pathway in human ovarian cancer. Oncogene 2000, 19:2324-2330.

11. Cheng JQ, Altomare DA, Klein MA, Lee WC, Kruh GD, Lissy NA, Testa JR: Transforming activity and mitosis-related expression of the AKT2 oncogene: evidence suggesting a link between cell cycle regulation and oncogenesis. Oncogene 1997, 14: 2793-2801.

12. Cheng JQ, Ruggeri B, Klein WM, Sonoda G, Altomare DA, Watson DK, Testa JR: Amplification of AKT2 in human pancreatic cells and inhibition of AKT2 expression and tumorigenicity by antisense RNA. Proc Natl Acad Sci USA 1996, 93: 3636-3641.

13. Lauffenburger DA, Horwitz AF: Cell migration: a physically integrated molecular process. Cell 1996, 84:359-369.

14. Miranti CK, Brugge JS: Sensing the environment: a historical perspective on integrin signal transduction. Nat Cell Biol 2002, 4:E83-E90.

15. Bacus SS, Altomare DA, Lyass L, Chin DM, Farrell MP, Gurova K, Gudkov A, Testa JR: Akt is frequently upregulated in HER-2/ neu-positive breast cancers and may contribute to tumor aggressiveness by enhancing cell survival. Oncogene 2002, 21:3532-3540.

16. Morini M, Mottolese M, Ferrari N, Ghiorzo F, Buglioni S, Mortarini R, Noonan DM, Natali PG, Albini A: The $\alpha_{3} \beta_{1}$ integrin is associated with mammary carcinoma cell metastasis, invasion, and gelatinase B (MMP-9) activity. Int J Cancer 2000, 87:336-342.

17. Masure S, Haefner B, Wesselink J-J, Hoefnagel E, Mortier E, Verhasselt $P$, Tuytelaars A, Gordon R, Richardson A: Molecular cloning, expression and characterization of the human serine/threonine kinase Akt-3. Eur J Biochem 1999, 265:353-360.

18. Sun M, Wang G, Paciga JE, Feldman RI, Yuan ZQ, Ma XL, Shelley SA, Jove R, Tsichlis PN, Nicosia SV, Cheng JQ: AKT1/PKB $\alpha$ kinase is frequently elevated in human cancers and its constitutive activation is required for oncogenic transformation in NIH3T3 cells. Am J Pathol 2001, 159:431-437.

19. Kim D, Kim S, Koh H, Yoon SO, Chung AS, Cho KS, Chung J: Akt/PKB promotes cancer cell invasion via increased motility and metalloproteinase production. FASEB J 2001, 15:1953-1962.

20. Park BK, Zeng $X$, Glazer RI: Akt1 induces extracellular matrix invasion and matrix metalloproteinase-2 activity in mouse mammary epithelial cells. Cancer Res 2001, 61:7647-7653.

21. Tanno S, Mitsuuchi Y, Altomare DA, Xiao GH, Testa JR: Akt activation up-regulates insulin-like growth factor I receptor expression and promotes invasiveness of human pancreatic cancer cells. Cancer Res 2001, 61:589-593.

22. Bellacosa A, de Feo D, Godwin AK, Bell DW, Cheng JQ, Altomare DA, Wan M, Dubeau L, Scambia G, Masciullo V, Ferrandina G, Benedetti Panici P, Mancuso S, Neri G, Testa JR: Molecular alterations of the AKT2 oncogene in ovarion and breast carcinomas. Int J Cancer 1995, 64:280-285.

23. Czauderna F, Fechtner M, Aygun H, Arnold W, Klippel A, Giese K, Kaufmann J: Functional studies of the PI(3)-kinase signalling pathway employing synthetic and expressed siRNA. Nucleic Acids Res 2003, 31:670-682.

\section{Correspondence}

Margaret Ashcroft, Cell Growth Regulation and Angiogenesis Laboratory, Cancer Research UK Centre for Cancer Therapeutics, Institute of Cancer Research, Sutton, Surrey SM2 5NG, UK. Tel: +44 208722 4035; fax: +44 208770 7899; e-mail: margaret.ashcroft@icr.ac.uk 